\title{
Initial validation of a simple, nonbiological, mechanical ERCP training model for cannulation and stent placement
}

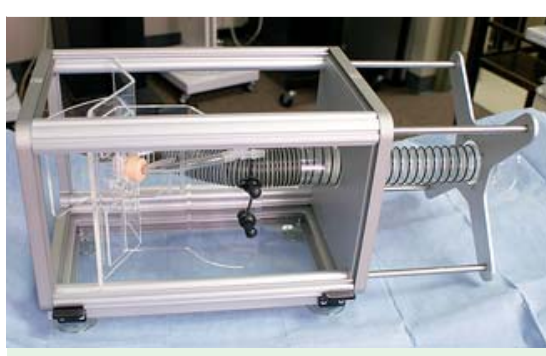

Fig. 1 The endoscopic retrograde cholangiopancreatography (ERCP) trainer consists of a metal cage, which serves to hold synthetic elements that comprise a model of the upper gastrointestinal and pancreaticobiliary tracts.

Few models are available for hands-on training in endoscopic retrograde cholangiopancreatography (ERCP). Moreover, the key aspect of learning ERCP properly is the acquisition of manual and visual skills [1,2]. Although performing ERCP procedures in human beings eventually leads to expertise, both experts and endoscopy societies strongly encourage that some of the key skills be acquired with the use of training models [3]. Herein, we show a simple ERCP model for training endoscopists in scope insertion, wheel handling, cannulation, and stent insertion. The model consists of a metal cage, which serves to hold synthetic elements that comprise a model of the upper gastrointestinal and pancreaticobiliary tracts ( Fig. 1, Video 1). The esophagus, stomach, and duodenal sweep are constructed from a plastic tube ( $\bullet$ Fig. 2 a). The papillae are made of latex, and the bile ducts are made of plastic. The pancreaticobiliary tree can be attached to the cage at various levels of difficulty ( Fig.2b).

The model was placed on a table, and ERCP was then performed by five trainees and by five endoscopists with and without ERCP experience ( $\bullet$ Video 1 ). An Olympus duodenoscope (TJF-Q180V; Olympus America, Center Valley, Pennsylvania, USA) was used. The endoscopists were filmed, observed, and guided by two ERCP experts ( $\bullet$ Fig.3, $\square$ Video 1 ). The endoscopists also filled out questionnaires on various aspects of the model, including endoscope handling, visual realism, usefulness, and performance. The model was useful for performing and training in the

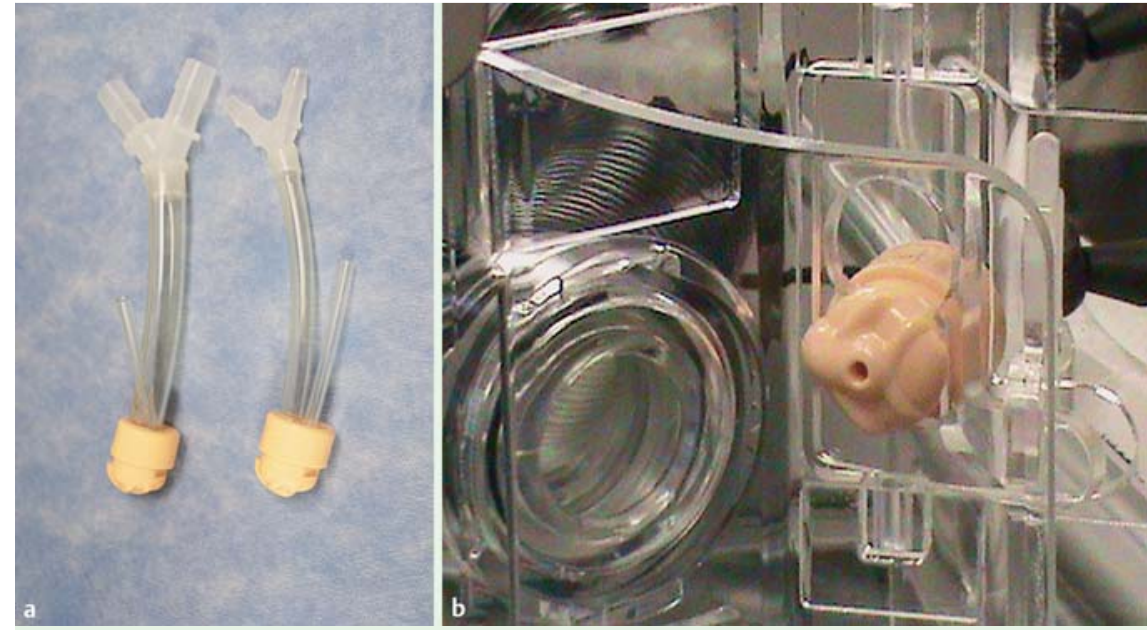

Fig. 2 Synthetic pancreaticobiliary tree. a The esophagus, stomach, and duodenal sweep are constructed from a plastic tube. $\mathbf{b}$ The pancreaticobiliary tree can be attached to the cage at various levels of difficulty.

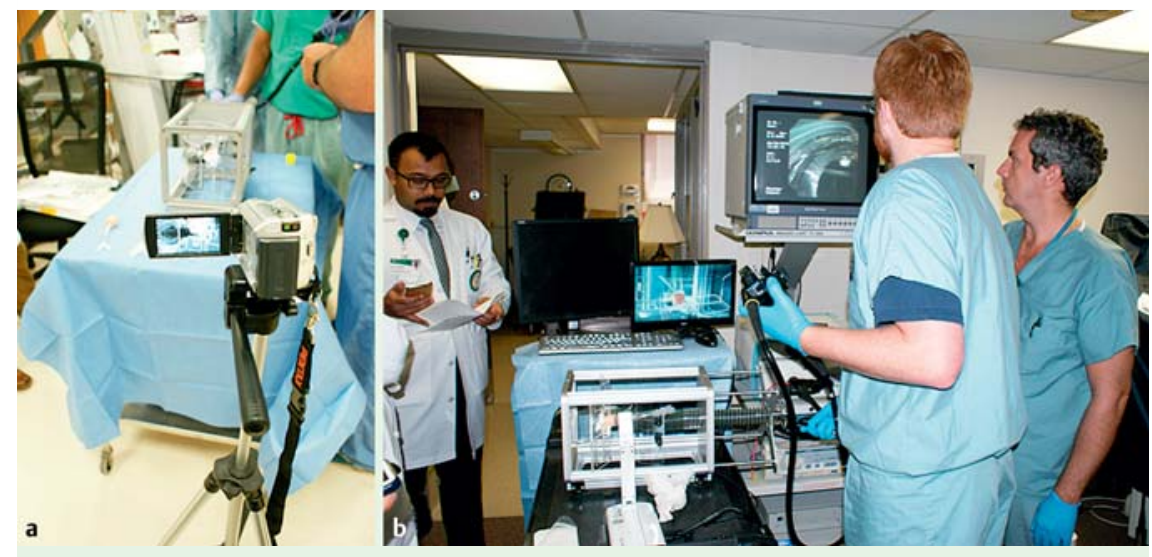

Fig. 3 a, b The endoscopists are filmed, observed, and guided by two experts in endoscopic retrograde cholangiopancreatography.

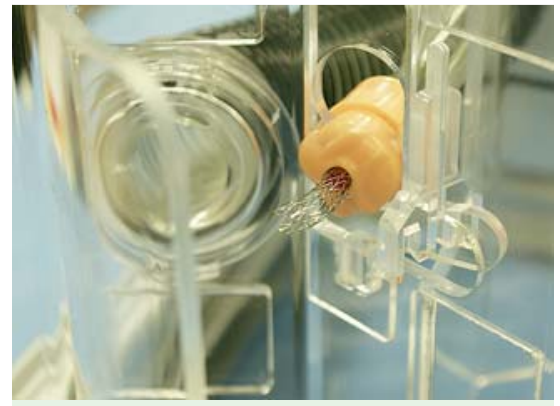

Fig. 4 Deployed metal stent. An advantage of this model is that it is possible to remove the stent and reuse the papilla several times to practice stent placement and other therapeutic interventions.

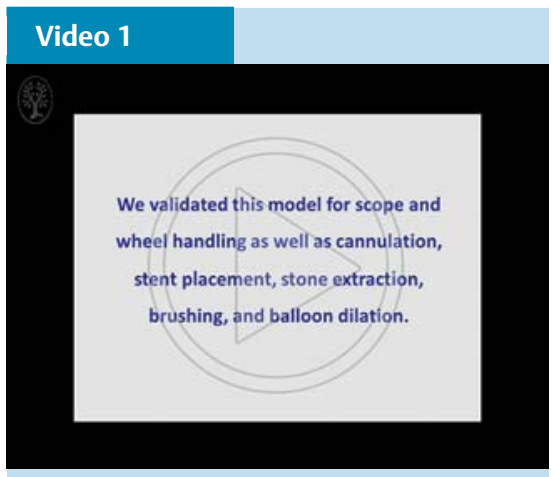

A simple, mechanical endoscopic retrograde cholangiopancreatography (ERCP) training model. 
following steps: (i) introducing and positioning the scope, (ii) handling the wheels and elevator, (iii) positioning and targeting the papilla, (iv) cannulating the bile ducts, and $(\mathrm{v})$ inserting plastic and metal stents ( $\bullet$ Fig. 4, $\bigcirc$ Video 1).

In summary, this model appears novel and useful for various reasons. First, it can be used in any endoscopy unit. Second, there is no need to buy or use special endoscopes because the model is nonbiological and does not contain any tissue. Thus, the endoscope may be cleansed during standard reprocessing. In contrast, biological live and nonlive teaching models can be used only in designated training rooms, and most of the endoscopic equipment must be purchased separately. Third, this model can potentially be distributed or brought to any unit, so that endoscopists in any part of the world have a chance to learn basic and advanced ERCP skills. Fourth, the papilla has a natural appearance with a strong resemblance to a "real-life" clinical scenario, allowing the endoscopist to acquire a feel for the various types of instruments used in ERCP. Fifth, we believe that for ethical reasons, it is important for endoscopists performing ERCP procedures to obtain their initial experience with training models, not in humans [4].

To the best of our knowledge, this is the first report of the feasibility of this model, which provides step-by-step explanations with video documentation, including instructions for inserting a self-expanding metal stent.

Endoscopy_UCTN_Code_TTT_1AR_2AB

Competing interests: None

\section{Ivan Jovanovic ${ }^{1}$, Lucia C. Fry' ${ }^{1}$, Nadan Rustemovic ${ }^{2}$, Branko Bilic ${ }^{2}$, Hrovje Ivekovic ${ }^{2}$, Marco D’Assunção', Klaus Mönkemüller ${ }^{1}$}

${ }^{1}$ Basil I. Hirschowitz Endoscopic Center of Excellence, Unit for Experimental Endoscopy and Advanced Endoscopy Training, Division of Gastroenterology and Hepatology, University of Alabama at Birmingham, Birmingham, Alabama, USA

2 Department of Gastroenterology, University Hospital Center Zagreb, Medical School of Zagreb, Zagreb, Croatia

\section{Acknowledgments}

The ERCP trainer was provided to our department for testing and training at no cost by Cook Medical, Winston-Salem, North Carolina, USA. The ERCP model was developed by Ivo Boškoski, MD, and Guido Costamagna, MD. Klaus Mönkemüller, $\mathrm{MD}, \mathrm{PhD}$, FASGE, is the 2014 recipient of an American Society of Gastrointestinal Endoscopy (ASGE) Endoscopic Research Award and has received honoraria from Cook Medical for lectures and hands-on training sessions given at Digestive Disease Week, which in 2015 was held in Washington, DC, USA. Ivan Jovanovic, MD, PhD, FASGE (a 2015 Fulbright Scholar) and Marco Aurelio D'Assunção, MD, are visiting professors at the University of Alabama at Birmingham, Birmingham, Alabama, USA. This work was done in part during their stay at the Basil I. Hirschowitz Endoscopic Center of Excellence of the University of Alabama at Birmingham.

\section{References}

1 Boix J, Lorenzo-Zúñiga V, Moreno de Vega Vet al. Identification of significant difficulty of selective deep cannulation by a simple predictive model: an endoscopic scale for teaching ERCP. Surg Endosc 2008; 22: $1678-1685$

2 Williams EJ, Taylor S, Fairclough P et al. BSG Audit of ERCP. Are we meeting the standards set for endoscopy? Results of a large-scale prospective survey of endoscopic retrograde cholangio-pancreatograph practice. Gut 2007; 56: $821-829$

3 Adler DG, Lieb JG 2nd, Cohen J et al. Quality indicators for ERCP. Gastrointest Endosc 2015; 81: 54-66

4 Kachaamy TA, Faigel DO. Improving ERCP quality and decreasing risk to patients and providers. Expert Rev Gastroenterol Hepatol 2013; 7: $531-540$

Bibliography

DOI http://dx.doi.org/

10.1055/s-0034-1393389

Endoscopy 2015; 47: E585-E586

(c) Georg Thieme Verlag KG

Stuttgart · New York

ISSN 0013-726X

Corresponding author

Klaus Mönkemüller, MD, PhD, FASGE

Division of Gastroenterology and Hepatology

Basil I. Hirschowitz Endoscopic

Center of Excellence

Endoscopy Unit, JT 664

619 19th Street S

Birmingham, AL 35249

USA

Fax: +1-205-297-9411

klaus1@uab.edu 